\title{
A POLÍTICA DOS DISCURSOS POLÍTICOS: AS DUAS RETÓRICAS DA SEGURANÇA PÚBLICA DO PARANÁ
}

\author{
Fábia Berlatto
}

\begin{abstract}
RESUMO
O artigo apresenta e discute o discurso da "segurança pública" tal como formulado e difundido pela Secretaria de Segurança Pública do Estado do Paraná. Esse discurso, parte importante da própria política de segurança pública, é analisado aqui como um dispositivo de controle social perverso. O uso do adjetivo "perverso" refere-se a um tipo de controle social que ao invés de primar pelo bem-estar social, investe simultaneamente na defesa retórica dos direitos humanos, na exaltação de critérios técnico-científicos de "guerra" ao crime, assim como em ações práticas de combate legal da pobreza. Essa estratégia faz parte de uma luta simbólica cujo efeito é, antes de tudo, criminalizar o Outro. No caso em análise, esse Outro é o pobre. Minha hipótese é que essa prática discursiva mobiliza duas doxas diferentes, direcionadas a públicos também diferentes. Sugiro que a adesão a essas doxas, dos direitos humanos e do combate técnico ao crime, estão ligadas a um jogo cujas regras são dadas pelas lutas no campo político. Esse processo faz parte não só do mecanismo de manutenção do monopólio do uso legítimo da força física e simbólica pelo Estado, mas também da luta político-eleitoral daqueles agentes do Estado que formulam e pronunciam esse novo discurso da segurança pública.
\end{abstract}

PALAVRAS-CHAVE: segurança pública; direitos humanos; controle social; controle social perverso.

\section{INTRODUÇÃO}

Na edição do jornal Folha de S. Paulo de 25 de maio de 2006, o Secretário de Segurança Pública do Estado do Paraná (SESP), Luiz Fernando Delazari, publicou um artigo intitulado "Do caos urbano ao caos social". O momento em que o Secretário escreveu seu texto era excepcional. Uma série de confrontos envolvendo policiais versus uma determinada organização de presidiários (o Primeiro Comando da Capital (PCC)) e seu aparato externo em diversas cidades do estado de São Paulo chocara o país - tanto quanto, se a comparação for possível, o espetáculo produzido a partir dos conflitos ocorridos na periferia de Paris no outono de 2005 chocara o mundo com as imagens da "desordem" e dos veículos incendiados. A mensagem do Secretário paranaense era que o Brasil estava tomando um caminho equivocado no combate ao que ele chamou de "caos urbano"; essa opção conduziria o país a uma "guerra sangrenta". O que o estado do Paraná teria então para ensinar sobre segurança pública aos demais estados (em especial a São Paulo) e ao governo federal?
Segundo o Secretário: “A política econômica adotada em nosso País há mais de dez anos gera altíssimo nível de desemprego, produz a fome e o desespero e transborda em um caos social quase incontrolável. Essa situação, aliada ao despreparo das polícias estaduais e federais e à nítida sensação de impunidade dos criminosos, fez eclodir um quadro de violência e insegurança que assola quase todas as regiões do PAIIS [sic]. [...] O apelo da população caminha no sentido de um endurecimento de políticas repressivas de segurança pública, como se essa violência pudesse ser combatida com a violência. Esse apelo, para ser atendido, passa necessariamente pelo desrespeito aos mais elementares direitos humanos. [...] Mas as estatísticas demonstram que os alvos mais freqüentes do combate policial continuam a ser, sobretudo, pessoas de camadas pobres e marginalizadas. Ao contrário de resolver o problema, acabam por gerar outros tantos. [...] A maioria dos mortos é pobre, morador das periferias e favelas dos grandes centros urbanos, vítima de um processo que os obriga ao enfrentamento armado das instituições públicas ou criminosas, gerando uma via de mão dupla de violência e insegurança. [...] 
Assim é que se abastece o mercado de criminosos. Assim é que a tensão derivada da miséria e a luta pela sobrevivência nas periferias sociais brasileiras se transforma inevitavelmente em uma guerra sangrenta"1 (DELAZARI, 2006; sem grifos no original).

No artigo, o Secretário demonstra seu conhecimento das injustiças sociais e sua indignação com o desrespeito sistemático aos direitos humanos, principalmente os das "camadas pobres e marginalizadas". Todavia, essa reflexão postula uma relação de causa e efeito tão geral e tão ampla que, no cálculo final, tudo explica tudo. Ou melhor, a relação de causa e efeito é tão simples que a primeira coisa que devemos fazer é desconfiar de sua lógica. Ou melhor: perguntar pela razão de ser dela.

Como o próprio título diz, "o caos urbano" leva ao "caos social". Isto é, a "tensão derivada da miséria e a luta pela sobrevivência" causam (ou têm causado) uma "guerra sangrenta". A "política econômica" (neoliberal, privatista etc., adotada inclusive pelo governo Lula) provoca "desemprego, fome, desespero e caos social incontrolável”. Edmundo Campos Coelho, já no final da década de 1970, chamava a atenção para o defeito de uma "Sociologia" que explica a criminalidade como decorrência da pobreza e do desemprego (cf. COELHO, 1978). Segundo ele, esse tipo de análise serve para alimentar a crença de que a grande maioria dos criminosos é oriunda da categoria social dos pobres, o que os torna responsáveis pelo clima generalizado de medo e insegurança dos grandes centros urbanos. É esse tipo de "pensamento", aliás, que tem informado, ainda hoje, o conteúdo e a direção das políticas de segurança pública.

Mas não é como pensador social que o Secretário de Segurança do Paraná interessa aqui. Seu discurso, naquilo que tem de paradigmático, é representativo de um tipo de leitura do mundo social. Esse discurso, e a prática que decorre dele, funciona, nas sociedades contemporâneas, como uma espécie de controle social perverso na medida em que reproduz e difunde determinados estigmas, preconceitos, pré-noções. Trata-se de um

${ }^{1}$ Luiz Fernando Delazari foi Secretário de Segurança Pública do Paraná entre 2003 e 2010; na época em que publicou esse artigo, era também vice-Presidente do Colégio Nacional dos Secretários de Segurança Pública. controle social que mantém e/ou amplia uma visão de mundo e uma divisão de mundo que consideram a criminalidade como "consequência da marginalidade" social (idem, p. 28). O resultado dessa concepção e das políticas de Estado que se legitimam através dela são as "cruzadas morais contra certos tipos de crime [o que Delazari chama de violência das ruas: assalto a mão armada, furto, a ponta inferior do tráfico etc.], pressões políticas ou da opinião pública, todas sempre circunstanciais e efêmeras, [que provocam] maior atividade policial repressiva e eleva[m] periodicamente as taxas oficiais de criminalidade" entre os pobres (idem, p. 43). Isso faz, sintomaticamente, com que a "distribuição espacial da pobreza dentro das cidades coincida sistematicamente com a [distribuição social] da criminalidade" (idem, p. 37).

O texto escrito pelo Secretário de Segurança Pública do Paraná (SESP) contém, de maneira exemplar, os dois problemas de que trato neste artigo.

Um deles, o problema teórico, envolve o argumento clássico de Weber em relação à noção e aos papéis do Estado moderno. Por Estado "deve entender-se um instituto político de atividade contínua, quando e na medida em que seu quadro administrativo mantenha com êxito o monopólio legítimo da coação física para a manutenção da ordem vigente" (WEBER, 1974, p. 43-44; sem grifos no original). Portanto, o monopólio da violência física não está desde sempre garantido pelo Estado. Ele deve ser reivindicado continuamente por um processo de conquista de legitimidade que, nas sociedades modernas, só será possível se repousar sobre ditames legais (leis, normas, códigos etc.). Dito isso, a arenga do Secretário é uma espécie de indício das práticas usualmente empregadas no processo de disputa do monopólio da violência física $e$ simbólica pelo Estado e por seus agentes. Essa disputa pelo poder da coerção legítima se dá também (e aqui, no caso que nos interessa, principalmente) no nível simbólico. Uma vez que esse monopólio da repressão legal depende da aptidão da instituição estatal em fazer reconhecer a validade de sua utilização exclusiva, o discurso do Secretário, enquanto discurso oficial, pode ser lido como uma ação que reivindica o monopólio da violência simbólica pelo Estado. Tal violência simbólica almeja legitimar-garantir o monopólio da violência física. 
O problema empirico deste artigo é verificar como se dá a luta pelo monopólio da violência física no domínio simbólico através dos discursos oficiais da segurança pública produzidos sistematicamente pela SESP-PR a partir de 2003. Todos os pronunciamentos dos agentes estatais responsáveis pela pasta da segurança pública no Paraná seguem a mesma linha e complementam o sentido do texto do Secretário apresentado no início deste artigo. Tentarei entender qual o significado dessa retórica para a política de segurança, quais seus objetivos (explícitos e implícitos) e qual sua consequência tanto sobre o pequeno mundo político do estado quanto sobre a sociedade como um todo. Concomitantemente, apresento algumas declarações dos moradores da Vila das Torres, uma favela central de Curitiba que é alvo constante de ações policiais. Esses testemunhos transmitem uma visão diferente sobre o que pode ser chamado de uma "natureza" (isso é, uma característica intrínseca) da polícia, produzida na experiência cotidiana dos moradores da Vila com esse braço do Estado.

As fontes analisadas aqui são, basicamente, documentos, artigos, entrevistas e declarações retiradas tanto da imprensa quanto dos sites oficiais da Agência Estadual de Notícias e da Secretaria de Estado da Segurança Pública - isso é, a voz institucional do Estado. O material foi separado (e interpretado) de acordo com três eixos de interesse principais: 1) a "filosofia" implícita da segurança pública no estado; 2) a crença dos agentes estatais nos instrumentos técnicos de repressão à violência criminal; 3) a visão sobre a política operacional de segurança pública que a SESP ao mesmo tempo postula e produz. Essa separação é meramente analítica. De fato, há, como se pode imaginar, uma integração entre esses três níveis discursivos. Entretanto, ainda que essas concepções se alimentem reciprocamente por um processo de reforço mútuo, elas se dirigem a audiências sociais distintas e têm objetivos políticos também distintos.

O que pretendo sugerir, em primeiro lugar, é que a retórica utilizada pela Secretaria e/ou pelo Secretário (seu porta-voz) para falar da política de segurança do governo tem um verniz "humanista". Chamarei essa retórica de "o discurso dos direitos humanos". Esse discurso é, ainda que não só, uma arma utilizada no contexto local em duas frentes. Ele funciona, de um lado, como um elemento importante do programa político do governo Requião (2003-2010) para dife- renciar-se dos governos estaduais anteriores ("neoliberais", "conservadores", "elitistas", "tecnocráticos" etc.). Por isso, essa retórica faz parte da política do estado do Paraná. De outro lado, esse discurso dos direitos humanos é uma arma poderosa na luta pelo processo de preservação do privilégio exclusivo da força física $e$ simbólica por parte do Estado. Assim, essa retórica "humanista" faz parte da política de Estado.

Esse segundo movimento diz respeito às formas pelas quais o Estado procura, através da retórica desse governo, se apropriar do direito de dizer o que a segurança pública deve ser e o que ela é. Por isso esse discurso e as representações sociais que decorrem dele constituem em uma doxa (BOURDIEU, 1994).

A doxa consiste em um consenso profundamente arraigado, em um senso comum, em um sistema simbólico - em grande parte fabricado que corresponde à estrutura social. Nas palavras de Bourdieu a doxa é, além disso, "um ponto de vista particular, o ponto de vista dos dominantes, que se apresenta e se impõe como ponto de vista universal; o ponto de vista daqueles que dominam ao dominar o Estado e que constituíram seu ponto de vista como ponto de vista universal fazendo o Estado" (idem, p. 129).

A prática discursiva da Secretaria de Estado da Segurança Pública do Paraná, diferentemente do que se poderia concluir de antemão, não está separada de sua prática repressiva, ainda que aquela mobilize politicamente a retórica cortês e correta dos "direitos humanos". A prática repressiva está apoiada no que se pode chamar de o "discurso da eficiência policial", que se daria pela utilização de critérios técnico-científicos de "guerra" ao crime. Esse segundo tipo de discurso não nega nem se opõe ao "discurso dos direitos humanos". A coexistência deles na mesma política-retórica de Estado é que constitui o problema. Nesse sentido, é preciso, para avaliar bem a questão, superar as críticas usuais sobre governos "que dizem uma coisa e fazem outra". Para entender a que regras implícitas e impensadas essa narrativa, que enfatiza - ao mesmo tempo - o respeito aos direitos humanos e a "guerra" contra o crime, colocando em prática uma política repressiva, obedece, é necessário investigar as relações que se estabelecem entre os agentes políticos no pequeno mundo da política e entre os agentes estatais e o público eleitor, em geral, no mundo social. 


\section{O DISCURSO DOS DIREITOS HUMANOS}

O âmbito da lei e da ordem manifesta de forma paradigmática os embates políticos e ideológicos entre a direita e a esquerda brasileiras. Isso ocorre porque esse tema "agrupa o conjunto de representações em dois pólos opostos: as representações populares que reputam ao crescimento da violência e dos crimes origens religiosas ou morais [a direita]; e as que atribuem uma causalidade sócio-econômica ao crescimento dos crimes e da violência em geral [a esquerda]" (Soares apud ADORNO, 2005, p. 21).

A classificação de Soares é útil para organizar a apresentação das narrativas da segurança pública no Paraná. Elas se submetem à mesma divisão binária esquerda-direita mencionada acima. A idéia, porém, não é encontrar contradições ideológicas em um governo de centro-esquerda (governo Roberto Requião), nem agrupar opiniões políticas em pólos opostos. Pretendo, antes disso, verificar como essa narrativa compatibiliza o respeito aos direitos humanos e as demandas por maior eficiência policial. Em um segundo momento, pretende-se entender qual a lógica desse processo.

O chavão peculiar da esquerda é o de que a violência não é um problema que cabe só à polícia resolver. O Secretário da segurança pública do Paraná define como "simplista" o pensamento que prega "reprimir, prender e atacar [os criminosos] como se segurança pública fosse uma guerra". Segundo Delazari, este tipo de visão, típica da direita, é um "contra-senso" por "querer transformar uma sociedade violenta" através de medidas de "repressão violenta".

Já as narrativas de moradores da Vila das Torres evidenciam como eles vivenciam ações da Secretaria de Segurança que, não obstante estejam em completa desconformidade com o que diz o Secretário, são cotidianas: "Teve um dia que estava indo para o centro e do outro lado da rua estava um menino correndo e o policial vinha atrás dele. O policial deu um tiro que matou o menino. Eu vi tudo. Essa foi a morte que mais me chocou" (depoimento de moradora; há 34 anos na Vila apud LAZAROTO, 2004, p. 69). "Aparentemente a crença é que se matar os adolescentes tudo se resolve. Será? Quem permitiu que a arma fosse parar nas mãos destas crianças? Até onde sabemos este tipo de munição pertence ao exército" (COMUNIDADE ARRUINADA, 2008). "A violência tem em todo lugar, mas a convivência da polícia com o pessoal daqui é diferente" (depoimento de moradora; há 25 anos na Vila apud LAZAROTO, 2004, p. 95).

O Secretário da SESP exalta que o caso do Paraná é exemplar por sua consciência social, por investir em outros âmbitos (sociais, educacionais) crendo investir em segurança pública. Vejamos como ele se expressa no trecho a seguir: "Delazari mostrou que a realidade criminal do Paraná está diretamente ligada às ações em setores como a educação e emprego. Hoje o Governo do Paraná investe mais de $30 \%$ em educação, facilita o acesso à energia elétrica com o [programa] Luz Fraterna, a criação do projeto Leite das Crianças, entre outras ações. Isso é investir em segurança também. O Estado deve acatar a origem do problema como a falta de emprego, a falta de oportunidades, que são as geradoras da criminalidade" (TAXA DE HOMICIDIO NO PARANÁ, 2008). "Estes programas sociais são muito importantes para a recuperação de um tecido social desgastado por más administrações governamentais anteriores" (ibidem).

A fala oficial procura demonstrar algo como uma "consciência de esquerda" diante do problema da segurança pública. Isso é visível tanto na relação direta entre pobreza e criminalidade que esse discurso postula, quanto na prioridade de temas relacionados aos direitos humanos que ele enfatiza, como os abusos de poder no exercício da contenção do crime e da violência.

Evidencia-se também aqui o jogo político explícito que busca contrapor o atual governo ao anterior (de Jaime Lerner, 1994-1998 pelo Partido Democrático Trabalhista (PDT-PR), e entre 1998 e 2002 pelo Partido Democratas DEM-PR)), contraposição que também é evidente na fala seguinte contra a prefeitura municipal comandada por Beto Richa (Partido da Social-Democracia Brasileira (PSDB-PR)), personagem que não está ligado politicamente à administração Requião (Partido do Movimento Democrático Brasileiro (PMDB-PR)): “A Vila Torres e o Parolin são das aglomerações populacionais mais antigas da cidade e que continuam desorganizadas por conta da falta de ações eficazes de um grupo politico que está há 20 anos no poder sem se preocupar em realizar melhorias definitivas nestas e em outras regiões. Obviamente que se isso acontecesse, se a área fosse trabalhada com seriedade pela prefeitura, o efeito seria sentido primeiro pelos locais 
vizinhos a estas regiões e com certeza por toda cidade, já que estas regiões muitas vezes são locais que servem de esconderijo para grandes bandidos. [...] Com certeza o criminoso jovem de hoje não foi apenas órfão de mãe ou de pai, mas $f o i$ órfão do poder público que não fez sua lição de casa social [sic]" (DELAZARI, 2008a).

Aqui há ainda um lapso do Secretário: se houvesse "melhorias" na Vila quem primeiro ganharia seria não a própria Vila das Torres, mas "os locais vizinhos", isso é, os bairros tradicionais de classe média que a circundam.

A próxima declaração é exemplar da consciência, entre uma parte dos moradores da Vila das Torres, da sua importância política, ou melhor, do papel que sua "situação social" tem para o uso político daqueles que disputam o poder no estado. A preocupação com a "situação social" (ou quaisquer jogos de palavras da mesma família) faz todo sentido no campo político: "Eu acho que o Estado não tem interesse em mudar nada aqui. É falta de interesse. Pra eles é melhor que fique assim, porque a Vila tem um valor político" (Informante 3).

À falta de sensibilidade das gestões estaduais anteriores e do governo atual do município, o Secretário contrapõe as seguintes palavras: "Não é difícil trazer a ordem [para a Vila das Torres]. O que parece difícil é levar a urbanização para lá, devolver a dignidade de vida para aquelas pessoas, recuperar o local através de fortes ações do poder público municipal. Não há no mundo polícia que resolva o problema da criminalidade que nasce do ódio, da falta de dignidade, da falta de emprego, da fome, da miséria. No caso da Vila Torres, a solução está efetivamente no empenho do poder público municipal em tirar aquela população da miséria para que não sejam reféns da criminalidade" (DELAZARI, 2008a; sem grifos no original).

Uma característica desse tipo de visão é reforçar a representação, bastante difundida $n a$ e também bastante criticada pela Sociologia, das "populações carentes" como potencialmente perigosas. O emigrante, com baixa instrução escolar, pobre, portador de hábitos não-urbanos, dono de uma moral gasta pela miséria é uma ameaça ao bem-estar de todos justamente porque é uma categoria social vulnerável às tentações da carreira criminal. Enfim, essa visão comum finaliza a construção de uma "subcultura marginal" (cf. COELHO, 1978), em que a criminalidade seria uma conseqüência direta e incontestável da pobreza.
É possível validar ainda mais essa interpretação ao expor o texto que descreve um programa social, promovido pela própria SESP, chamado Blitz da Cidadania [sic]. Essa blitz seria solução para o problema da falta de condições sociais de vida que os moradores enfrentam, para o gozo de seus direitos como membros de um Estado e traria, enfim, "dignidade de vida para aquelas pessoas" (isto é, os pobres).

O programa "promove a cidadania através da aproximação efetiva dos policiais civis e militares com os moradores das comunidades mais carentes de todo o Paraná. A Blitz é uma espécie de feira de serviços da segurança pública que leva gratuitamente até essas regiões escolhidas [onde moram os pobres] confecção de carteiras de identidade, cursos de primeiros-socorros, dicas de segurança, palestras de prevenção sobre violência doméstica e violência contra crianças, adolescentes e mulheres e diversos outros programas de auxílio à população. A Coordenadoria de Ações Comunitárias [da SESP] [tem] o objetivo de incluir projetos sociais de inclusão e promoção da cidadania como mais uma política pública de combate à criminalidade"2 (PARANÁ. SECRETARIA DE ESTADO DA SEGURANÇA PÚBLICA DO PARANÁ, 2008a; sem grifos no original).

Como se lê, trata-se de um jogo de palavras que prima, no exemplo acima, pelo controle social via políticas assistencialistas ou via facilidades burocráticas. Elas são sintomaticamente confundidas com políticas de integração social que promoveriam, no fim de tudo, a segurança pública de todos.

Vejamos um discurso, que não é do Secretário, mas foi retirada do portal da SESP e refere-se às ações sociais voltadas para "as camadas marginalizadas". Dele consta que as ações "sociais" do governo do estado trarão "reflexos ainda mais positivos na área de segurança pública e nos quadros assustadores, que hoje são apresentados, de

\footnotetext{
2 E por falar em "contra-senso", a palavra "blitz", que vem do alemão Blitzkriegen, é uma expressão militar para designar uma "ofensiva poderosa realizada de surpresa"; "uma guerra-relâmpago [historicamente, na Segunda Guerra Mundial foi usada com fins expansionistas, pelos alemães, contra países da Europa]". É também uma expressão policial, para se referir à batida, "especialmente de caráter inesperado e que mobiliza grande aparato", conforme o Dicionário Houaiss da Língua Portuguesa.
} 
crimes, homicídios, prostituição e trabalho infantil". E consta, ainda, que: "Quando as pessoas começam a melhorar seus padrões de vida, [elas] deixam de enveredar para ações desesperadas em busca da sobrevivência" (ZIMMERMANN, $2005)^{3}$.

Esse tipo de interpretação, presente seja no discurso do estado, seja nos textos da imprensa, torna-se ainda mais grave ao darmo-nos conta de que, além de serem elas que formam e informam a opinião das classes média e alta, também são elas que representam a visão de mundo dominante dessas últimas sobre o assunto. Essas palavras ampliam e legitimam as demandas dessas categorias sociais por ações públicas de cunho policial na ânsia por sua segurança individual.

A utilização de um tipo de patrulha de polícia voltada especificamente para o problema da "delinqüência juvenil" é outro exemplo do que afirmei até aqui. Ao analisar políticas públicas focadas na juventude em Curitiba, Moraes (2005) fala em "policialização" dos jovens, um mecanismo de controle social baseado exclusivamente em práticas policiais no tratamento com os moradores, principalmente jovens, das favelas.

A SESP colocou em prática um programa chamado "Patrulha Escolar", que tinha como justificativa "a união da comunidade escolar com a polícia para reduzir a violência e a criminalidade nas escolas e nas suas proximidades" (PARANÁ. SECRETARIA DE ESTADO DA SEGURANÇA PÚBLICA DO PARANÁ, 2008c). Assim, os órgãos repressores - em especial a polícia - tornaram-se os principais parceiros do Estado na promoção da pacificação social, inclusive no âmbito escolar ${ }^{4}$.

Outro fator recorrente nas narrativas da SESP é o seu acompanhamento da evolução do debate e das experiências internacionais das últimas déca-

\footnotetext{
3 O padre Roque Zimmermann foi Secretário do Trabalho, Emprego e Promoção Social durante as gestões de Roberto Requião como Governador do Paraná (2003-2010).

4 Moraes afirma que a Patrulha Escolar, "baseada na cultura do medo e na criminalização da juventude [...] foi e tem sido utilizada para resolver conflitos e problemas que deveriam ser objeto de tratamento pela escola e pelos professores, uma vez que costumam ocorrer problemas de indisciplina e conflitos absolutamente comuns ao universo escolar, o que é muito claramente percebido pelos próprios policiais" (MORAES, 2008, p. 12). Cf. Sallas (1999).
}

das para a redução do crime e da violência. É perceptível a busca incessante em afirmar o compromisso do governo com a segurança de forma "inovadora", "revolucionária", "moderna", tentando sempre romper com o modelo tradicional de policiamento. Assim, tudo o que se fez no estado é novidade (tanto em relação às administrações políticas anteriores quanto ao que já se fez no restante do país).

Uma evidência desse concurso à novidade promovido pela SESP é a constante ostentação do fato de as polícias do Paraná terem aderido à filosofia "revolucionária" da Polícia Comunitária. Vejamos exemplos: segundo Delazari, aqui o "serviço de policiamento comunitário é modelo para o Brasil", ou "o atual governo realiza a maior modificação estrutural da segurança pública no Paraná" (DELAZARI, 2008a).

O trecho a seguir, da agência oficial de notícias oficiais, em que está incluído um pronunciamento do Governador Roberto Requião, define bem como esse modelo de polícia comunitária foi adaptado no Paraná: "Eles [os policiais] se apresentarão aos moradores, identificando-se e entregando um cartão com nome e fotografia, além de cartilhas com dicas de segurança. 'A polícia conhecida é mais responsável pelos seus atos, porque será identificada em tudo aquilo que fizer e, em compensação, terá mais segurança para agir na comunidade, porque é bem-vinda, é amiga da comunidade e é conhecida e reconhecida por todos', comentou o Governador Requião (REQUIÃO, 2008)".

Essa estratégia de aproximação da comunidade é também uma tentativa de fomentar/recuperar a legitimidade da polícia: "A polícia tem trabalhado para mudar sua imagem, para se aproximar da sociedade, para se transformar numa polícia solidária, numa polícia fraterna, uma polícia que inclusive compartilha os problemas de segurança, pois nós precisamos de parceria com a sociedade" (ibidem; sem grifos no original).

Apesar de o problema estar colocado aqui em termos de "imagem", toda ação está dedicada a recuperar a legitimidade do monopólio da violência prática e principalmente simbólica do Estado através do aparelho policial.

Mas vejamos como a relação polícia-comunidade dá-se - na prática - na Vila das Torres: "Esses dias os policiais passaram, eu ouvi, e disse- 
ram pra uma turma [de jovens] que tava ali: 'Nós que estamos deixando vocês folgarem aí, mas na hora que a gente quiser a gente acaba com vocês" (Informante 4). "Agora nem PM e Civil vêm aqui mais, só vem a Rotam e a Rotam só vem pra matar. Se você ver a Rotam circulando aí pode saber que vão matar" (Informante 2). "Mas ainda poderia ser melhor se o governo desse um pouco mais de atenção aos moradores e pedisse para a polícia respeitar um pouco mais os moradores, ao invés de mandar fechar a Vila e tratar todos como vagabundos" (declaração de pessoa que mora há 45 anos na Vila apud LAZAROTO, 2004, p. 33).

A nova "imagem" é imediatamente desacreditada pela prática policial efetiva. A propósito, os moradores, especialistas em segurança pública na prática, identificam mais e melhor que o governo do estado uma das principais fontes do problema da legitimidade policial. A questão seria então a seguinte: é permitido confiar e admirar uma "polícia fraterna" [sic] onde os agentes policiais estão eles próprios doentes? "Quanto aos "excessos" de violência cometidos por alguns policiais, pergunta-se: é possível que um tenente ou um coronel não percebam quando um subordinado está quimicamente dependente ou emocionalmente abalado? Quem está doente emocionalmente ou dependente quimicamente precisa de um médico, não pode assumir um trabalho de base como o de policial" (COMUNIDADEARRUINADA, 2008).

Apesar de um artigo ufanista no portal da SESP ter afirmado ser de autoria do Governador Requião a invenção da participação da comunidade no trabalho da polícia, sabe-se que esta é uma ação que teve origem no Japão após a II Guerra Mundial, mas que ganhou ênfase nos anos de 1970 e 1980 na América do Norte e Europa Ocidental, tornando-se conhecida internacionalmente. "Mesmo antes de ser vista por especialistas de todo o mundo como uma idéia inovadora e revolucionária para a segurança pública, a participação da comunidade no trabalho da polícia já havia sido aplicada pelo Governador Roberto Requião em seu mandato anterior [1991-1994]. É uma percepção visionária de que a parceria da população, prestando informações à polícia, reduziria os índices de violência, já que possibilitaria um trabalho mais pontual e certeiro contra a ação de criminosos. Infelizmente, essa filosofia foi abandonada por outros governos, que não perceberam, na comunidade, uma aliada essencial para as instituições policiais" (PARANÁ. SECRETARIA DE ESTADO DA SEGURANÇA PÚBLICA DO PARANÁ, 2008 c; sem grifos no original).

Em que pese a imaginação social do governador, os culpados pelo fracasso seriam os outros políticos, insensíveis ao problema, sem essa "percepção visionária", sem essa intuição sobre a maneira de reduzir "os índices de violência".

Em busca de maior eficiência recorre-se à colaboração da comunidade, que se converte em "parceira" na prestação de serviços de segurança. Segundo Mesquita (2004), algumas análises sugerem que o maior envolvimento de policiais com problemas locais e maior participação dos cidadãos nas atividades policiais enfraquecem as responsabilidades tradicionais do poder público em suas atribuições exclusivas de executar policiamento preventivo e repressivo, bem como investigar crimes e apontar seus possíveis autores. A crítica desse modelo de policiamento também parte dos moradores da Vila das Torres: "Quem deve encontrar os "bandidos" é a comunidade? Será que assim não inverteremos os papéis? Será que essa postura não é perigosa? Seria o aluno que ensina o conteúdo programático ao professor? É o paciente que medica o doutor? É a assembléia que prega o sermão ao pastor? A impressão aparente é de que a estrutura reguladora da segurança nas cidades está à espera de um novo regulador" (COMUNIDADE ARRUINADA, 2008).

Se para a maior parte dos setores políticos de esquerda não há muito que fazer no que concerne à violência se não ocorrer uma mudança "estrutural" que afete radicalmente a distribuição da riqueza e da propriedade, para a direita a resposta ao problema estaria em um endurecimento na aplicação da lei e da ordem, proposta que assimila velhas fórmulas que incluem contratação de novos policiais e modernização de equipamentos, mediante compra de armas estrangeiras, por exemplo (Soares apud ADORNO, 2002, p. 22).

\section{O DISCURSO DA EFICIÊNCIA POLICIAL}

A modernização das polícias paranaenses e da gestão da segurança pública é outro lugar-comum nas narrativas da SESP. Há relatos de encontros, congressos, debates, no Brasil e no exterior, freqüentados pelo Secretário em busca de tecnologia, modernidade, "produção" tanto de idéias científicas quanto de equipamentos para a segurança pública. "Os mais modernos conceitos sobre se- 
gurança pública apontam que somente o investimento em tecnologia e a profissionalização da gestão em segurança é que garantem bons resultados no combate à criminalidade. No Paraná, $a$ era do 'amadorismo' ficou para trás através da concretização de grandes projetos tecnológicos de combate à violência. Entre eles estão o Mapa do Crime, o Boletim de Ocorrência Unificado, a Modernização do Instituto de Identificação, a ampliação do Departamento de Inteligência, entre outras ações" (PARANÁ. SECRETARIA DE ESTADO DA SEGURANÇA PÚBLICA DO PARANÁ, 2008d; sem grifos no original).

A parceria com instituições internacionais ${ }^{5}, \mathrm{o}$ investimento financeiro, a compra de aparelhos, o treinamento dos policiais também são medidas enfatizadas por esse discurso. "Em 2005, foram contratados 1033 policiais militares, 205 atendentes civis para o Ciosp (190) e 316 bombeiros. Mais de nove mil alunos passaram por cursos de reciclagem. Também 5762 armas e 992 viaturas foram compradas para as polícias. Apenas em reformas de delegacias, foram investidos cerca de R \$ 2,8 milhões, no ano passado" (PARANÁ. SECRETARIA DE ESTADO DA SEGURANÇA PÚBLICA DO PARANÁ, 2006). “O orçamento da Secretaria da Segurança Pública do Paraná, que será executado em 2008, será o dobro do valor gasto, na área, em 2003 (definido pelo governo estadual anterior)" (PARANÁ. SECRETARIA DE ESTADO DA SEGURANÇA PÚBLICA DO PARANÁ, 2008b).

Essa ideologia da prática, isto é, esse discurso ideológico que explica e justifica a prática do Estado e dos seus agentes de segurança, está bem expresso na declaração do Secretário Luiz Fernando Delazari: “A polícia está com rendimento muito alto, organizada, bem equipada e trabalhando com inteligência. Isso resulta em muitas prisões", afirmou. Delazari destacou que, em média, mais de 100 pessoas são presas, por dia,

\footnotetext{
5 Como por exemplo, com a Senlis Council, instituição inglesa com base em alguns países como França, Canadá, Afeganistão e Brasil, que promove políticas públicas para melhorar a gestão de ações de combate ao tráfico de drogas. Há um ano no Brasil, com um escritório permanente no Rio de Janeiro, a instituição tem o seu foco principal no combate ao narcotráfico. Segundo seu site, em breve a instituição irá estabelecer no Rio de Janeiro um centro internacional de excelência nas políticas de segurança pública.
}

no Paraná, ou três mil novos presos por mês. "Nós triplicamos praticamente o número de vagas existentes no sistema prisional. Mas a criminalidade tem sido combatida com muita eficiência e isso tem gerado superpopulação no sistema ou em delegacias" (DELAZARI, 2008c).

Para todos os efeitos, essa concepção faz parte de outra doxa, a doxa da ação, da prática da segurança. Ela representa aquilo que a "boa sociedade" quer ouvir e quer que o governo faça. Esse tipo de enunciado oficial traz uma perspectiva diferente da encontrada no discurso dos direitos humanos, que visava assim, além do campo político, aos "formadores de opinião". A exposição da prática da segurança pública e dos seus feitos voltase, por seu turno, para a sociedade como um todo, para o cidadão comum, o cidadão médio, o "pai de família" etc. Para cada caso, portanto, há uma linguagem e uma mensagem apropriada.

No entanto, a percepção dos moradores da Vila das Torres sobre a melhoria material, ou técnica, da polícia toca em conflitos muito maiores e expõe dilemas profundos que se opõem às expectativas presentes nas narrativas da SESP: "A polícia está doente. O que você acha de abrir a porta da sua casa e dar de cara com policiais se drogando e agindo como se nada estivesse acontecendo? Eu acho que deve haver uma renovação da polícia. Essa situação toda só vai mudar se $60 \%$ da polícia for renovada. Estou dizendo que $60 \%$ da polícia deve ser demitida e que novos policiais isentos de vício em drogas, corrupção, bem preparados devem ser contratados" (Informante 1).

Acrescentam-se ainda a essa avaliação bem mais realista casos de corrupção: "Eles vêm aqui [os policiais] só para fazer negócio. É o seguinte: você tem uma arma ou drogas, eles dizem que se certa quantia não for paga eles irão prender. Se não tem dinheiro pra pagar na hora, eles parcelam: 'tal hora eu passo aqui para pegar $\mathrm{R} \$ 500$, tal hora eu volto pra pegar mais $\mathrm{R} \$ 500$, se você não tiver, eu te prendo'. Daí o que acontece é que muita gente vai roubar no semáforo para pagar essa dívida com a polícia. É assim. Outras vão roubar no semáforo para comprar suas drogas" (Informante 1).

É até certo ponto paradoxal que à melhoria da estrutura material e técnica da polícia corresponda uma deterioração moral dos policiais. A visão retrospectiva (com todas as cautelas que se deve tomar diante da necessidade psicológica de ro- 
mancear o passado) do tempo imaginado em que na polícia "só havia pessoas de bem" dá a medida do que se quer dizer. "Antigamente quando o Módulo da Polícia era onde é o Clube das Mães, era melhor. A polícia agia, pegava e levava, corrigia melhor. Ninguém comprava a polícia (depoimento de moradora da Vila apud LAZAROTO, 2004, p. 51). "Quando vim morar em definitivo no bairro, a polícia era totalmente diferente, só havia pessoas de bem" (depoimento de moradora da Vila apud LAZAROTO, 2004, p. 72).

Contra as expectativas do senso comum governamental, nem tudo se resolve comprando mais viaturas. Anderson argumenta que nesse período histórico chamado de "pós-modernidade" a eficiência é a palavra-chave na legitimação da ciência a serviço do poder (cf. ANDERSON, 1999). A retórica da eficiência fornecida por dispositivos científicos é continuamente acionada pelo discurso da segurança pública no Paraná e temos um bom exemplo disso na exposição sobre uma ferramenta moderna chamada de Mapa do crime, que, segundo consta, "transforma a gestão da Segurança Pública" com a ajuda de "especialistas": "A partir dessa ferramenta o Paraná administra a segurança pública de forma profissional e científica", afirmou o Secretário. Ele lembrou que a informação é hoje o principal instrumento de trabalho da polícia, seja ela Civil, Militar ou Científica e que com os dados gerados pelo sistema é possível orientar de forma dinâmica a atividade policial em qualquer nível" (DELAZARI, 2008c; sem grifos no original). Delazari destacou que a Coordenadoria de Análise e Planejamento Estratégico, criada para gerir o Mapa do crime, trabalha a partir de equipe multidisciplinar composta por policiais, estatísticos, economistas, antropólogos, geógrafos, sociólogos, que fazem um estudo detalhado de todas as nuances da criminalidade.

Acredito que esse tipo de narrativa oficial, para além de buscar angariar a simpatia do cidadão médio e, por extensão, do eleitor em potencial, torna-se uma importante fonte de um tipo de controle social que nomeio aqui de perverso. Perverso no sentido de não ser "natural", ou seja, de ser forjado graças à e por meio da violência simbólica. A violência simbólica é, por exemplo, exercida não na confecção do Mapa do crime, mas na sua exaltação como a última palavra em matéria de segurança pública. $O$ poder e a legitimidade científica dessas conclusões que o Mapa tira contri- buem decisivamente para apontar o espaço do pobre como o locus por excelência da criminalidade. Essa violência, no nível simbólico, forma e ao mesmo tempo representa a "opinião pública". A opinião pública constitui-se, então, em uma força poderosa no jogo do controle social perverso.

As narrativas oficiais da segurança pública no Paraná pretendem estar em perfeita conformidade com as estratégias gerais de prevenção e controle da criminalidade de inúmeros países avançados, como Inglaterra, França e Estados Unidos. Essas abordagens discursivas falam de uma política de segurança confiável, consistente, preventiva, baseada nas comunidades, cujo planejamento é balizado a partir de informações estatísticas. Trata-se de uma política ao mesmo tempo "humana" e "científica", ainda que a serviço da repressão policial.

Esse jogo de palavras, tão presente em todas as falas e documentos do governo, chama a atenção para a aptidão dos porta-vozes oficiais do saber técnico para esculpir a realidade, arquitetando uma representação definida do mundo social a partir de esquemas conceituais abstratos (isso é, que fazem abstração da realidade social). Bourdieu afirma que quando se trata do mundo social, "as palavras criam as coisas", pois elas criam o consenso sobre a existência e o sentido das coisas, elas criam o senso comum, isso é, a doxa aceita por todos como dada (BOURDIEU, 1996, p. 127). A doxa da segurança pública deve produzir, por meio das declarações dos agentes do estado do Paraná - portanto, no domínio do universo do Estado - uma representação oficial da política oficial de segurança tão perto daquilo que se quer ouvir quanto distante daquilo que os moradores da Vila das Torres vivem na realidade.

\section{CONSIDERAÇÕES FINAIS}

O que se quis enfatizar aqui é que o uso político das narrativas oficiais sobre a segurança pública paranaense, mesmo quando se pretendem fontes de esclarecimento da opinião pública, servem antes como mecanismo de um tipo de controle social não baseado em formas de promoção universal de bem-estar social.

Apesar de ter ficado evidente o abismo entre a abstração discursiva oficial e as ações policiais, percebidas pelas narrativas de moradores da Vila Torres, a intenção não foi separar o discurso da segurança pública de sua prática efetiva, mas evi- 
denciar um ponto que parece ter escapado à maioria das análises: as narrativas da segurança fazem parte de uma esfera diferente da prática da segurança pública, isto é, elas fazem parte do jogo político.

Essa separação não é tão óbvia como parece. A percepção comum assume como evidente que, em geral, o discurso nega a prática. A idéia aqui é que a prática complementa o discurso desde que se entenda que essas duas coisas referem-se a campos de ação diferentes, tem objetivos diferentes e, principalmente, públicos diferentes.

A retórica da SESP obedece às regras do campo político - ou mais exatamente, às regras da disputa política desse universo em especial. Essa "política do discurso político" (ou o que esses políticos profissionais dizem) busca legitimidade diante da opinião pública "culta". De olho no governo anterior, eles falam aquilo que imaginam que uma parte da sociedade quer ouvir, essa parte constituída pelos "formadores de opinião", ou seja, jornalistas, professores, categorias de profissionais liberais, políticos, comunicadores etc.

Ao pronunciar o que agrada os bem-pensantes, ao aderir à doxa da opinião pública "culta", a SESP requisita para si um discurso legitimador de seu poder e de sua autoridade. Assim, ao fazer uma abstração da prática da segurança pública, a SESP busca legitimar o monopólio da violência física e simbólica. Essa é uma maneira simbólica de lutar pelo monopólio da violência física e simbólica.

Os discursos da SESP do Paraná obedecem à natureza particular do jogo político local. Um dos interesses desse jogo político é a busca da superação do governo estadual anterior. No caso, ele é tido como um governo técnico, de retórica fria, que não continha "humanidade", não continha "profundidade" (sensibilidade) em relação aos assuntos "humanos". Nesse jogo, a adesão a essa doxa requer como retribuição a legitimidade dessa política, mas não só: requer também prestígio, notoriedade e, principalmente, distinção para quem formula e pronuncia o novo discurso da segurança.

Fábia Berlatto (fabiaberlatto@yahoo.com.br) é Mestre em Sociologia pela Universidade Federal do Paraná (UFPR).
Esse é o ponto, penso eu, mais interessante a ser destacado no discurso da segurança pública no Paraná. A exaltação da vocação humanista e, ao mesmo tempo, da eficácia técnica não funciona meramente como uma maquiagem da prática da segurança pública. Esses dois âmbitos da retórica da SESP serão tanto mais eficazes quanto mais conseguirem acertar o alvo exato ao qual se dirigem. No caso da defesa abstrata dos direitos humanos, o objetivo são os formadores de opinião. São discursos políticos (embora queiram se passar por análises sociais) que pretendem reforçar a doxa da opinião pública "culta" sobre a boa política de segurança. Já no caso da justificação da eficácia técnica da política de segurança, a finalidade é a sociedade em geral, o cidadão médio, o cidadão comum, o "pai de família". Nesse registro, calha usar outra linguagem, mais apropriada. Esse outro linguajar exalta a solução imediata dos problemas, a eficiência da polícia, a capacidade repressora do Estado. Tal concepção faz parte também de outra doxa, a doxa da ação, da prática da segurança. Ela representa aquilo que a "boa sociedade" quer ouvir e quer que o governo faça.

Se o discurso político sobre os "direitos humanos" mirava os adversários políticos do governo atual, o discurso da prática da segurança pública visa conquistar o público eleitoral. Ele pretende não convencer racionalmente, mas persuadir politicamente, de tal maneira que a eficiência da polícia possa (deva) se traduzir, mais adiante, em votos. A diferença em relação ao discurso "humanista" é que se aquele pretende que este governo seja diferente, o segundo tipo de discurso, o da efetividade, quer mostrar que os operadores do atual governo são melhores. Essa divisão não é consciente nem fabricada, isso é, não é mera jogada de marketing. Esses discursos políticos, embora tenham um conteúdo diferente, uma audiência diferente e um objetivo diferente, encontram-se em um ponto específico. Ao identificarem, para todos os fins, crime e marginalidade social, perpetuam os rituais de degradação da categoria social dos pobres. Por isso, tais narrativas funcionam como um tipo de controle social perverso. 


\section{REFERÊNCIAS BIBLIOGRÁFICAS}

ADORNO, S. 2002. O monopólio estatal da violência na sociedade brasileira contemporânea. In: MICELI, S. (org.). O que ler na ciência social brasileira 1970-2002. São Paulo: Sumaré.

ANDERSON, P. 1999. As origens da pósmodernidade. Rio de Janeiro: J. Zahar.

BAYLEY, D. H. 2001. Padrões de policiamento. São Paulo: USP.

BERLATTO, F. 2008. Controle social perverso: análise de uma política de segurança pública. Curitiba. Dissertação (Mestrado em Sociologia). Universidade Federal do Paraná.

BOURDIEU, P. 1994. Raisons pratiques. Paris: Seuil.

1996. Razões práticas. Sobre a teoria da ação. Campinas: Papirus.

COELHO, E. C. 1978. A marginalização da criminalidade e a criminalização da marginalidade. Revista de Administração Pública, Rio de Janeiro, n. 12, p. 139-161.

DELAZARI, L. F. 2006. Do caos urbano ao caos social. Folha de S. Paulo, p. A-3, 25.maio. Disponível em: http://www.aenoticias.pr. gov.br/modules/news/article.php? storyid=20978. Acesso em: 10.jun.2008.

2008a. Pelo fim do estigma. Gazeta do Povo, Curitiba, Caderno Vida e Cidadania, 17.nov. Disponível em: http://portal.rpc. com.br/gazetadopovo/vidaecidadania/ conteudo.phtml?tl=1\&id=828765\&tit=Pelofim-do-estigma. Acesso em: 17.nov.2008.

2008b. Agência Estadual de Notícias, Curitiba, 28.ago. Disponível em: http:// www.aenoticias.pr.gov.br/modules/news/ article.php? storyid=38524. Acesso em: 28.ago.2008. 2008c. Agência Estadual de Notícias, Curitiba, 12.jun. Disponível em: http:// www.aenoticias.pr.gov.br/modules/news/ article.php? storyid $=37558$. Acesso em: 12.jun.2008.

LAZAROTO, A. 2004. Como ela é: a Vila das Torres contada por seus moradores. Curitiba: Linguaruda.

MESQUITA, P. 2004. Policiamento comunitário e prevenção do crime: a visão dos coronéis da Polícia Militar. São Paulo em Perspectiva, São Paulo, v. 18, n. 1, p. 103-110, mar.

MORAES, P. R. B. 2005. Punição, encarceramento e construção de identidade profissional entre agentes penitenciários. São Paulo: IBCCRIM.

REQUIÃO, R. 2008. Agência Estadual de Notícias, Curitiba, 12.jun. Disponível em: http:// www.aenoticias.pr.gov.br/modules/news/ article.php?storyid=2226. Acesso em: 12.jun. 2008.

SALLAS, A. L. F. (org.). 1999. Os jovens de Curitiba: desencantos e esperanças - juventude, medo e violência. Brasília: UNESCO.

SOARES, L. E. (org.). 1996. Violência e politica no Rio de Janeiro. Rio de Janeiro: RelumeDumará.

ZIMMERMANN, R. 2005. Queda no índice pobreza refletirá na segurança, prevê Governo. Curitiba, 30.nov. Disponível em: http:// www.historico.aen.pr.gov.br/modules/noticias/article.php?storyid=16757. Acesso em: 15.set.2011.

WACQUANT, L. 2001. As prisões da miséria. Rio de Janeiro: J. Zahar.

WEBER, M. 1974. Ciência e política: duas vocações. São Paulo: Cultrix.

\section{OUTRAS FONTES}

Comunidade arruinada. 2008. Gazeta do Povo, Curitiba, Caderno Vida e Cidadania, 28.out. Disponível em: http://portal.rpc.com.br/ gazetadopovo/vidaecidadania/conteudo. phtml?tl=1\&id=822208\&tit. Acesso em: 28. out.2008. 
PARANÁ. SECRETARIA DE ESTADO DA SEGURANÇA PÚBLICA DO PARANÁ. 2006. Investimentos em segurança pública são multiplicados em 14 vezes. Curitiba, 5.jul. Disponível em: http://www.historico.aen.pr.gov.br/ modules/noticias/article.php?storyid= 22019\&tit= Investimentos-em-seguranca-publica-sao-multiplicados-em-14-vezes. Acesso em: 12.set.2011.

2008a. Blitz da Cidadania. Disponível em: http://www.seguranca.pr.gov.br/modules/ conteudo/conteudo.php? conteudo $=23$. Acesso em: 12.set.2011.

2008b. Orçamento da Segurança Pública passa de $R \$ 1,2$ bi e é o dobro que o de 2003. Curitiba, 12.jun. Disponível em: http:// www.conseg.pr.gov.br/modules/noticias/ makepdf.php?storyid=14. Acesso em: 12.set.2011.

2008c. Programa patrulha na escola. Curitiba, 12.jun. Disponível em: http:// www.seguranca.pr.gov.br/programas patrulha_escolar.php. Acesso em: 12.jun.2008.

2008d. Agência Estadual de Notícias, Curitiba, 12.jun. Disponível em: http:// www.aenoticias.pr.gov.br/modules/news/ article.php?storyid=22019. Acesso em: 12.jun.2008.

Taxa de homicídio no Paraná é menor do que média nacional. 2008. Agência Estadual de Notícias, Curitiba, 12.jun. Disponível em: http:/ /guiasjp.com/opcoes.php?option= $5 \&$ click $=25742 \&$ pubb $=0$. Acesso em: 12.set.2011. 
THE POLITICS OF POLITICAL DISCOURSE: TWO RHETORICS OF PUBLIC SAFETY IN THE STATE OF PARANÁ

\section{Fábia Berlatto}

This article presents and debates the discourse of "public safety" as it has been formulated and disseminated by the Secretariat of Public Safety for the State of Paraná. This discourse, an important part of public safety policy, is seen here as a perverse social control device. Our use of the adjective "perverse" makes reference to a type of social control that, instead of aiming at social welfare, invests simultaneously in a defensive rhetoric of human rights, exaltation of technical and scientific criteria for the "war against crime" and practical actions for a legal war on poverty. This strategy is part of a symbolic struggle with the overall effect of the criminalization of the Other - in this case, the poor. My hypothesis is that this discursive practice mobilizes two different doxas, directed toward different publics. I suggest that adherence to one or the other - the doxa of human rights, or of crime-fighting - is linked to a game whose rules are given by struggles in the political field. This process is not only part of mechanisms of State monopoly over the legitimate use of symbolic and physical force but also of political and electoral struggle of the State agents who formulate and pronounce these new discourses of public safety.

KEYWORDS: public safety; human rights; social control; perverse social control. 


\section{LA POLITIQUE DES DISCOURS POLITIQUES : LES DEUX RHÉTORIQUES DE LA SÉCURITÉ PUBLIQUE DU PARANÁ}

Fábia Berlatto

Résumé : L'article présente et discute le discours de la « sécurité publique », tel comme il est formulé et diffusé par l'Office de Sécurité Publique de la Région du Paraná. Ce discours, considéré comme une partie importante de la politique de sécurité publique elle-même, est analysé ici autant qu'un dispositif de contrôle social pervers. L'utilisation de l'adjectif « pervers », fait référence à un type de contrôle social qui investit simultanément sur la défense rhétorique des droits humains, sur l'exaltation des critères techniques et scientifiques de « guerre » à la criminalité, ainsi comme sur des actions pratiques de combat légal à la pauvreté, au lieu de s'investir plutôt au bien-être social. Cette stratégie fait partie d'un combat symbolique, dont l'effet est la criminalisation de l'autrui. Dans le cas sous analyse, l'autrui c'est le pauvre. Mon hypothèse, c'est que cette pratique discursive mobilise deux opinions différentes, dirigées à des publics aussi différents. Je suggère que l'adhésion à ces opinions, celle des droits humains et celle du combat technique au crime, est liée à un jeu dont les règles sont données par les luttes dans le domaine politique. Ce processus fait partie du mécanisme d'entretien du monopole de l'utilisation légitime de la force physique et symbolique par l'Etat, tout comme de la lutte politique et électorale des agents de $1^{6}$ Etat qui formulent et prononcent ce nouveau discours de la sécurité publique.

MOTS-CLÉS: la sécurité publique ; les droits humains ; le contrôle social ; le contrôle social pervers. 